\title{
PKM $\zeta$ Maintains Drug Reward and Aversion Memory in the Basolateral Amygdala and Extinction Memory in the Infralimbic Cortex
}

\author{
Ying-Ying He ${ }^{1,2,3}$, Yan-Xue Xue ${ }^{2,3}$, Ji-shi Wang*,', Qin Fang', Jian-Feng Liư', Li-Fen Xue ${ }^{2}$ and Lin Lu*,2 \\ 'Affiliated Hospital and School of Pharmacy of Guiyang Medical University, Guiyang, China; ${ }^{2}$ National Institute on Drug Dependence, \\ Peking University, Beijing, China
}

\begin{abstract}
The intense associative memories that develop between drug-paired contextual cues and rewarding stimuli or the drug withdrawalassociated aversive feeling have been suggested to contribute to the high rate of relapse. Various studies have elucidated the mechanisms underlying the formation and expression of drug-related cue memories, but how this mechanism is maintained is unknown. Protein kinase $M \zeta(P K M \zeta)$ was recently shown to be necessary and sufficient for long-term potentiation maintenance and memory storage. In the present study, we used conditioned place preference (CPP) and aversion (CPA) to examine whether PKM $\zeta$ maintains both morphine-associated reward memory and morphine withdrawal-associated aversive memory in the basolateral amygdala (BLA). We also investigate the role of PKM $\zeta$ in the infralimbic cortex in the extinction memory of morphine reward-related cues and morphine withdrawal-related aversive cues. We found that intra-BLA but not central nucleus of the amygdala injection of the selective PKM $\zeta$ inhibitor ZIP I day after CPP and CPA training impaired the expression of CPP and CPA I day later, and the effect of ZIP on memory lasted at least 2 weeks. Inhibiting PKM $\zeta$ activity in the infralimbic cortex, but not prelimbic cortex, disrupted the expression of the extinction memory of CPP and CPA. These results indicate that PKM $\zeta$ in the BLA is required for the maintenance of associative morphine reward memory and morphine withdrawal-associated aversion memory, and $\mathrm{PKM} \zeta$ in the infralimbic cortex is required for the maintenance of extinction memory of morphine reward-related cues and morphine withdrawal-related aversive cues. Neuropsychopharmacology (201 I) 36, 1972-1981; doi:I0.1038/npp.201 I.63; published online I June 201 I
\end{abstract}

Keywords: PKM $\zeta$; conditioned place preference; conditioned place aversion; memory; amygdala; infralimbic cortex

\section{INTRODUCTION}

Drug addiction is a chronic brain disease with a high rate of relapse (Leshner, 1997; O'Brien et al, 1992; O'Brien and McLellan, 1996). Despite years of abstinence from drugs, relapse can occur when addicts encounter cues, including people or places, associated with their prior drug use (Childress et al, 1988). The intense associative memories that develop between drug-paired contextual cues and the rewarding stimuli or drug withdrawal-associated aversive feeling have been suggested to contribute to the high rate of relapse among addicts (Hyman et al, 2006; Nestler, 2001; Robbins et al, 2008). Many neurotransmitters, neurotrophic

*Correspondence: Professor J-s Wang, Affiliated Hospital of Guiyang Medical College, Guiyang 550004, China, Tel: +86 851 6757898 , Fax: + 86 851 675 7898, E-mail: jswang_yg@yahoo.com or

Professor L Lu, National Institute on Drug Dependence, Peking University, Beijing I00191, China, Tel: +86 108280 2459, Fax: + 86 106203 2624, E-mail: linlu@bjmu.edu.cn

${ }^{3}$ These authors contributed equally to this work.

Received 31 December 20 10; revised 16 February 2011; accepted 21 March 2011 factors, and protein kinases have been delineated in the regulation of the formation and expression of drug-associated reward memories and withdrawal-associated aversive memories (LaLumiere and Kalivas, 2008; Lee and Messing, 2008; Ron and Jurd, 2005; Russo et al, 2009; Wise, 2008). However, few studies have reported the molecular bases of the maintenance and persistence of drug-related memories.

Protein kinase $\mathrm{M} \zeta(\mathrm{PKM} \zeta)$, which lacks the $N$-terminal regulatory domain, is a constitutively active $\mathrm{PKC} \zeta$ isoform that can enhance excitatory synaptic transmission by increasing the number of active postsynaptic AMPA receptors (Ling et al, 2006). PKM $\zeta$ has been shown to mediate the maintenance of late-long-term potentiation (LTP) through upregulation of the $\mathrm{N}$-ethylmaleimide sensitive fusion (NSF)/ glutamate receptor 2 (GluR2)-dependent AMPA receptor trafficking pathway (Yao et al, 2008). Persistently active kinase has also been implicated in memory mechanisms. PKM $\zeta$ is a key molecule in the maintenance of spatial memory, conditioned taste aversion memory, fear memory, recognition memory, and instrumental memory in various brain sites, including the insular cortex, hippocampus, amygdala, and sensorimotor cortex (Hardt et al, 2010; Kwapis et al, 2009; 
Madronal et al, 2010; Pastalkova et al, 2006; Serrano et al, 2008; Shema et al, 2007, 2009; von Kraus et al, 2010). PKM $\zeta$ activity is not required for the processing of contextually imprecise or procedural information, indicating that $\mathrm{PKM} \zeta$ may be involved in the maintenance of specific types of memories. Extinction is an active learning process that suppresses a previously conditioned response (Peters et al, 2009). N-methyl-D-aspartate (NMDA) receptors, metabotropic glutamate receptor 5 (mGluR5), cannabinoid $\mathrm{CB}_{1}$ receptors, norepinephrine, protein kinase $A$ (PKA), and M-type potassium channels in the infralimbic cortex have been implicated in the retrieval and consolidation of extinction memory in some memory tasks, including fear memory, conditioned taste aversion, and cocaine selfadministration (Burgos-Robles et al, 2007; Fontanez-Nuin et al, 2010; Lin et al, 2009; Mueller et al, 2008; Santini and Porter, 2010). However, the mechanisms by which extinction memories are maintained have not been investigated.

In our recent study, we investigated the role of $\mathrm{PKM} \zeta$ activity in the nucleus accumbens core in reward memory. We found that persistent PKM $\zeta$ activity in the nucleus accumbens core mediates the maintenance of cue memories associated with morphine, cocaine, and high-fat palatable food ( $\mathrm{Li}$ et al, 2011). PKM $\zeta$ activity in the nucleus accumbens core (or shell) did not mediate the maintenance of memories of cues previously paired with aversive opiate withdrawal symptoms ( $\mathrm{Li}$ et al, 2011). Therefore, the present study investigated whether $\operatorname{PKM} \zeta$ activity in the basolateral amygdala (BLA), a brain site implicated in emotional memories and drug reward memories (Peters et al, 2009; Phelps and LeDoux, 2005; Robbins et al, 2008), mediates the maintenance of drug-associated reward memory and drug withdrawal-associated aversive memory. We also investigated the role of $\mathrm{PKM} \zeta$ in the infralimbic cortex in the maintenance of the extinction of the memory of drug reward-related cues and drug withdrawal-related aversive cues.

\section{MATERIALS AND METHODS}

\section{Subjects}

Sprague-Dawley male rats, weighing 220-240 g, were obtained from the Laboratory Animal Center, Peking University Health Science Center. They were housed in groups of five in a temperature $\left(23 \pm 2{ }^{\circ} \mathrm{C}\right)$ - and humidity (50 $\pm 5 \%)$-controlled animal facility with free access to food and water. They were kept on a reverse $12 \mathrm{~h} / 12 \mathrm{~h}$ light/dark cycle. All treatments were performed in accordance with the National Institutes of Health Guide for the Care and Use of Laboratory Animals, and the procedures were approved by the local Committee of Animal Use and Protection.

\section{Drugs}

Morphine sulfate (Qinghai Pharmaceutical, Xining, China) and naloxone $\mathrm{HCl}$ (Sigma-Aldrich, St Louis, MO) were dissolved in $0.9 \%$ physiological saline and injected in a volume of $1 \mathrm{ml} / \mathrm{kg}$. Morphine and naloxone were injected subcutaneously (s.c.). The PKM $\zeta$ inhibitor ZIP (myrSIYRRGARRWRKL-OH; catalog no. 539624, Calbiochem,
Darmstadt, Germany) and scrambled ZIP (catalog no. 3215, Tocris, Missouri) were dissolved in saline (the vehicle). The control group received vehicle injections.

\section{Surgery}

Rats (weighing 280-300g when surgery began) were anesthetized with sodium pentobarbital (50 mg/kg, i.p.). Guide cannulae (23 gauge; Plastics One, Roanoke, VA) were bilaterally implanted $1 \mathrm{~mm}$ above the BLA/central nucleus of the amygdala (CeA) and infralimbic cortex/prelimbic cortex. The coordinates for the BLA and CeA (Paxinos and Watson, 2005) were the following: BLA (anterior/ posterior, $-2.9 \mathrm{~mm}$; medial/lateral, $\pm 5.0 \mathrm{~mm}$; dorsal/ ventral, $-8.5 \mathrm{~mm}$ ) and CeA (anterior/posterior, $-2.9 \mathrm{~mm}$; medial/lateral, $\pm 4.2 \mathrm{~mm}$; dorsal/lateral, $-7.8 \mathrm{~mm}$ ). The coordinates for the infralimbic cortex and prelimbic cortex were the following: infralimbic cortex (anterior/posterior, $+2.9 \mathrm{~mm}$; medial/lateral, $\pm 1.0 \mathrm{~mm}$; dorsal/ventral, $-4.8 \mathrm{~mm}$ ) and prelimbic cortex (anterior/posterior, $+2.9 \mathrm{~mm}$; medial/ lateral, $\pm 1.0 \mathrm{~mm}$; dorsal/ventral, $-3.0 \mathrm{~mm}$ ). The cannulae were placed at a $6^{\circ}$ angle toward the midline to avoid penetration of the lateral ventricle. The cannulas were anchored to the skull with stainless-steel screws and dental cement. A stainless-steel stylet blocker was inserted into each cannula to keep them patent and prevent infection. The rats were allowed to recover for 5-7 days after surgery.

\section{Intracranial Injections}

ZIP (10 and $30 \mathrm{nmol} /$ side $/ 0.5 \mu \mathrm{l})$ and scrambled ZIP ( $30 \mathrm{nmol} /$ side) were injected bilaterally into the BLA, CeA, infralimbic cortex, and prelimbic cortex with Hamilton syringes connected to 30 gauge injectors (Plastics One). The doses of the different compounds were based on our previous study (Li et al, 2011). A total volume of $0.5 \mu \mathrm{l}$ was injected bilaterally over $1 \mathrm{~min}$, and the injector was kept in place for an additional $1 \mathrm{~min}$ to allow for diffusion. At the end of the experiments, the rats were anesthetized with sodium pentobarbital $(100 \mathrm{mg} / \mathrm{kg}$, i.p.) and transcardially perfused. Cannula placements were assessed using Nissl staining with a section thickness of $40 \mu \mathrm{m}$ under light microscopy. Rats with misplaced cannulas were excluded from the statistical analysis.

\section{Conditioned Place Preference}

Conditioned place preference (CPP) was performed using an unbiased, counterbalanced protocol (Li et al, 2008, 2010; Wang et al, 2008). The CPP apparatus consisted of five identical three-chamber polyvinyl chloride (PVC) boxes. Two large-side chambers $(27.9 \mathrm{~cm}$ long $\times 21.0 \mathrm{~cm}$ wide $\times$ $20.9 \mathrm{~cm}$ high) were separated by a smaller chamber $(12.1 \mathrm{~cm}$ long $\times 21.0 \mathrm{~cm}$ wide $\times 20.9 \mathrm{~cm}$ high with a smooth $\mathrm{PVC}$ floor). The two larger chambers differed in their floor textures (bar and grid, respectively) and provided distinct contexts that were paired with morphine or saline injections. Three distinct chambers were separated by manual guillotine doors.

Baseline preference was assessed by placing the rats in the center compartment of the CPP apparatus. The rats were allowed free access to all compartments for $15 \mathrm{~min}$. The rats 
that showed a strong unconditioned preference ( $>540 \mathrm{~s}$ ) for one compartment were excluded. On subsequent conditioning days, the rats were trained for 8 consecutive days with alternating injections of morphine $(10 \mathrm{mg} / \mathrm{kg}$, s.c.) or saline $(1 \mathrm{ml} / \mathrm{kg}$, s.c.) in both compartments. After each injection, the rats were confined to the corresponding conditioning chambers for $45 \mathrm{~min}$ and then returned to their home cages. Tests for the expression of morphine-induced CPP in a drugfree state (15 min duration) were performed on different days after training (see below). The procedure during testing was same as during the initial baseline preference assessment. The CPP score was defined as the time (in seconds) spent in the morphine-paired chamber minus the time spent in the salinepaired chamber during CPP testing.

\section{Naloxone-Precipitated Morphine Withdrawal-Induced Conditioned Place Aversion}

The conditioned place aversion (CPA) procedure for naloxone-precipitated opiate withdrawal was based on previous work (Azar et al, 2003). The procedure included three phases, similar to morphine-induced CPP described above: baseline preference test, CPA training, and CPA expression test. Baseline preference was assessed by placing the rats in the center compartment of the CPP apparatus. The rats then were allowed free access to all of the compartments for $15 \mathrm{~min}$. The rats that showed a strong unconditioned preference ( $>540 \mathrm{~s}$ ) for one compartment were excluded. The CPA training included four 2-day cycles. In each cycle, naloxone-precipitated opiate withdrawal was paired with one of the chambers for $45 \mathrm{~min}$ on 1 day, and 'no withdrawal' was paired with the other chamber on the other day. Naloxone-precipitated withdrawal was induced by injecting morphine $(5 \mathrm{mg} / \mathrm{kg}$, s.c.), followed $4 \mathrm{~h}$ later by naloxone $(0.3 \mathrm{mg} / \mathrm{kg}$, s.c.). The rats were confined to the chamber immediately after the naloxone injection. The 'no withdrawal' condition included two injections of saline $(1 \mathrm{ml} / \mathrm{kg}) 4 \mathrm{~h}$ apart. The rats were confined to the 'no withdrawal' chamber for $45 \mathrm{~min}$ immediately after the second injection. The 15-min tests for the expression of naloxoneprecipitated opiate withdrawal-induced CPA were conducted in a drug-free state at different time points following CPA training and ZIP injections. During testing, the rats were allowed to freely explore the chambers of the apparatus. The CPA score was defined as the time (seconds) spent in the naloxone-precipitated withdrawal-paired chamber minus the time spent in the no withdrawal-paired chamber.

\section{CPP and CPA Extinction Training}

The CPP and CPA extinction training was performed on 8 consecutive days, and the procedure was similar to the establishment of CPP and CPA, with the exception that morphine and naloxone were replaced by saline. The CPP or CPA test was performed 1 day after the final extinction training session.

\section{Special Experiment}

Experiment 1: effects of $P K M \zeta$ inhibition in the amygdala on morphine-associated reward memory. We used four groups of rats ( $n=7-9$ per group) to determine the effects
Timeline
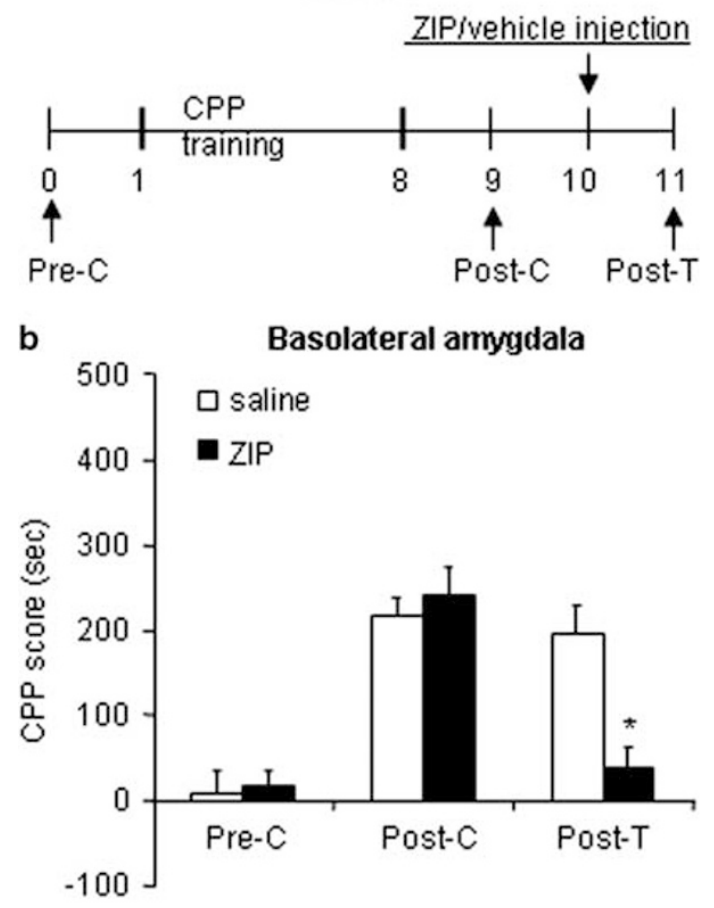

C

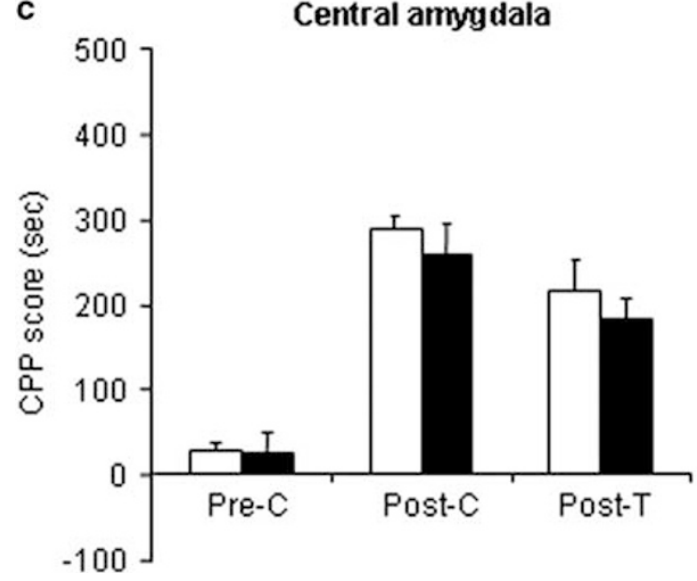

Figure I A single application of ZIP in the BLA, but not CeA, abolishes morphine-associated reward memory. (a) Timeline of experimental procedure. (b, c) The PKM $\zeta$ inhibitor ZIP (30 nmol/side) and its vehicle were microinfused bilaterally into the BLA (b) or CeA (c) I day after testing morphine CPP expression. Morphine-induced CPP was tested I day later. Data are expressed as the mean \pm SEM of preference score in seconds (time spent in the morphine-paired chamber minus time spent in the salinepaired chamber) during the CPP tests. $* p<0.05$, different from control group ( $0 \mathrm{nmol} / \mathrm{side}$ ZIP treatment group).

of PKM $\zeta$ inhibition in the amygdala on morphineassociated reward memory (Figure 1a). The rats were trained for morphine-induced CPP for 8 days and tested for the expression of CPP on day 9 without any injections (post-C). On day 10, the rats were injected with ZIP or vehicle into the BLA or CeA. Twenty-four hours after the injection, the expression of CPP was retested (post-T).

Experiment 2: duration of the effects of ZIP in the BLA on morphine reward memory. To further determine whether the effect of ZIP on morphine reward memory 
Timeline

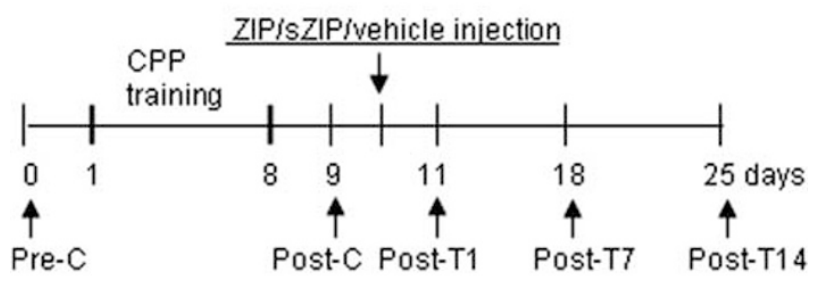

b

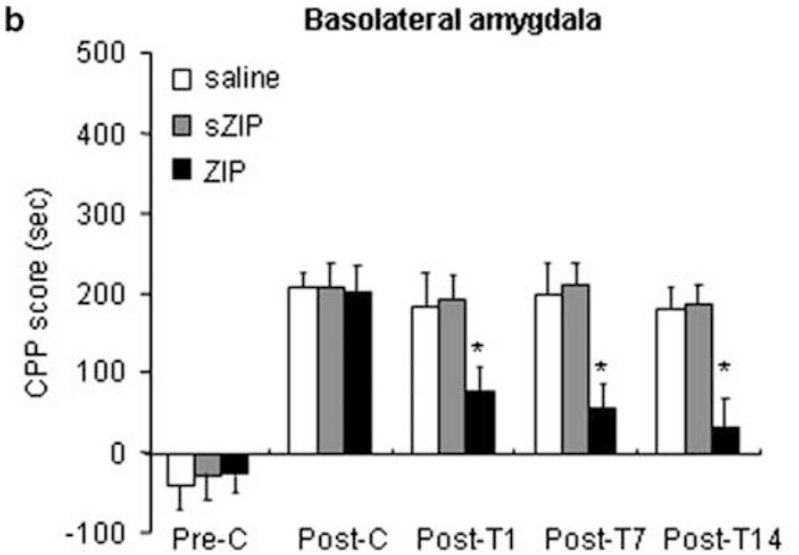

Figure 2 The effect of ZIP in the BLA on morphine reward memory is long lasting. (a) Timeline of experimental procedure. (b) The $P K M \zeta$ inhibitor ZIP ( $30 \mathrm{nmol} / \mathrm{side}$ ), inactive version of ZIP (scr-ZIP; $30 \mathrm{nmol} / \mathrm{side}$ ), and its vehicle were microinfused bilaterally into the BLA I day after testing morphine CPP expression. CPP testing was repeated I, 7, and 14 days later. Data are expressed as the mean \pm SEM of preference scores in seconds (time spent in the morphine-paired chamber minus time spent in the saline-paired chamber) during the CPP tests. ${ }^{*} p<0.05$, different from control group.

is long lasting, three groups of rats ( $n=7-9$ per group) were trained for morphine-induced CPP and then treated with ZIP ( $30 \mathrm{nmol} / \mathrm{side})$, scrambled ZIP ( $30 \mathrm{nmol} / \mathrm{side})$, or vehicle into the BLA (Figure $2 \mathrm{a}$ ). On days 11, 18, and 25 , these rats were tested again (post-T1, post-T7, and post-T14) for morphine-induced CPP without any injections.

Experiment 3: effects of $P K M \zeta$ inhibition in the amygdala on morphine withdrawal-associated aversive memory. The purpose of this experiment was to investigate the effects of the PKM $\zeta$ inhibitor ZIP in the amygdala on morphine withdrawal-associated aversive memory (Figure 3a). Four groups of rats ( $n=8-9$ per group) underwent CPA training. The rats were tested for the expression of CPA on day 9 without any injections (post-C). On day 10, the rats were injected with ZIP ( $30 \mathrm{nmol} / \mathrm{side})$ or vehicle into the BLA or CeA. Twenty-four hours after the injection, the expression of CPA was retested (post-T).

Experiment 4: effects of $P K M \zeta$ inhibition in the prefrontal cortex on morphine-induced CPP extinction memory. We used four groups of rats ( $n=7-9$ per group) to determine the effects of $\mathrm{PKM} \zeta$ inhibition in the prefrontal cortex on morphine-induced CPP extinction memory (Figure 4a). The rats were trained for morphine-induced CPP for 8 days and tested for the expression of CPP on
Timeline

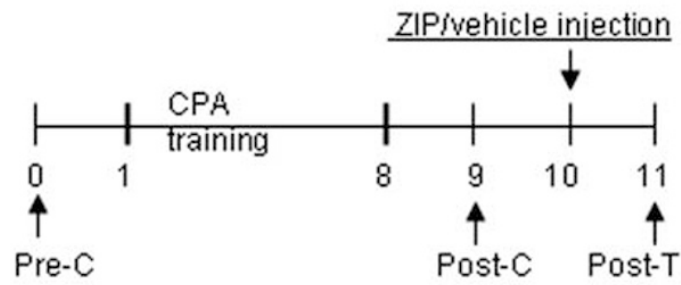

b

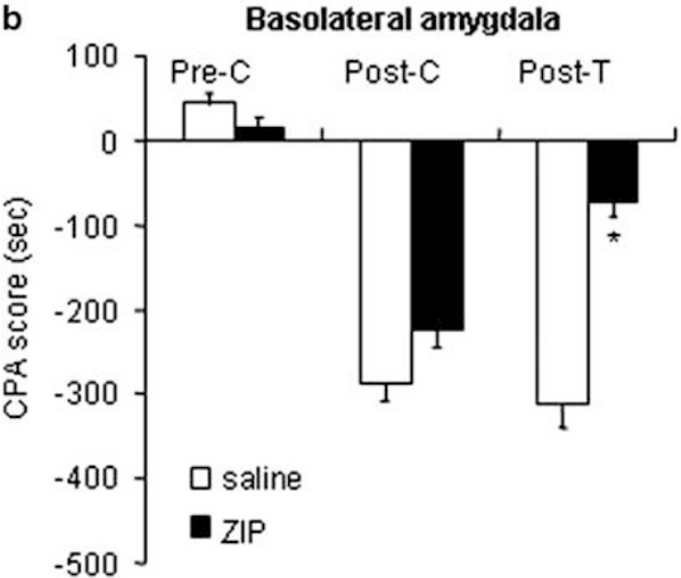

C

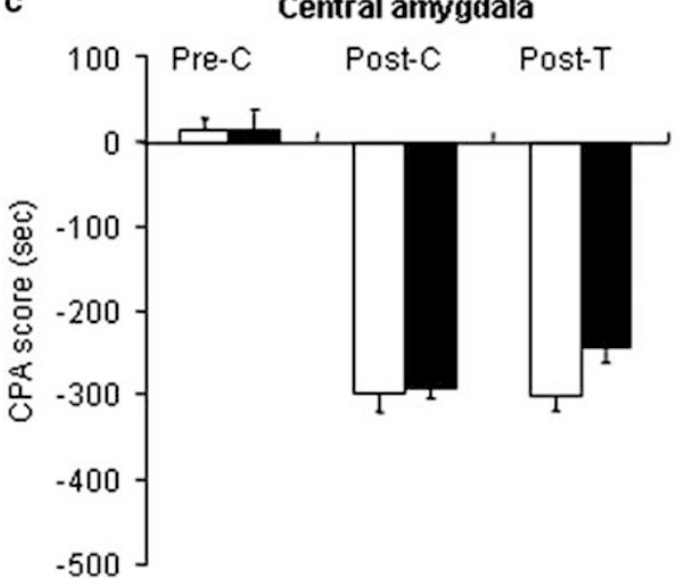

Figure 3 Inhibition of $\mathrm{PKM} \zeta$ in the $\mathrm{BLA}$, but not $\mathrm{CeA}$, disrupts the maintenance of morphine/naloxone-associated aversive memory. (a) Timeline of experimental procedure. $(b, c)$ The PKM $\zeta$ inhibitor ZIP ( $30 \mathrm{nmol} / \mathrm{side}$ ) and its vehicle were microinfused bilaterally into the BLA (b) or CeA (c) I day after the CPA test. Morphine withdrawal-induced CPA was tested I day later again. Data are expressed as the mean \pm SEM of aversion scores in seconds (time spent in the morphine withdrawal-paired chamber minus time spent in the saline-paired chamber) during the CPA tests. $* P<0.05$, different from control group $(0 \mathrm{nmol} / \mathrm{side}$ ZIP treatment group).

day 9 (post-C). The rats then underwent 8 consecutive days of extinction training. On day 18 , the rats underwent another CPP test to confirm that CPP was extinguished (post-E). On day 19, the rats were injected with ZIP ( $30 \mathrm{nmol} / \mathrm{side})$ or vehicle into the two subdivisions of ventral medial prefrontal cortex, infralimbic cortex, or prelimbic cortex. Twenty-four hours after the injection, the expression of CPP was retested (post-T). 
a

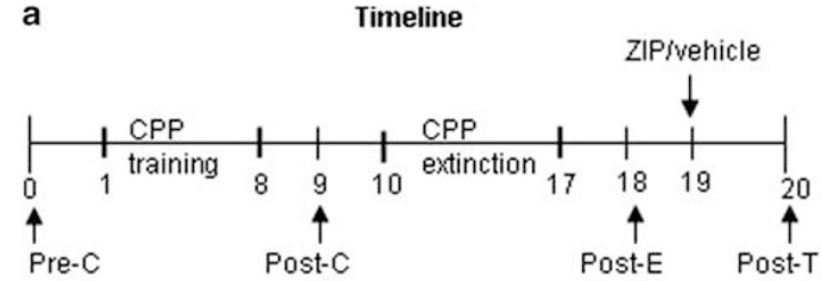

b

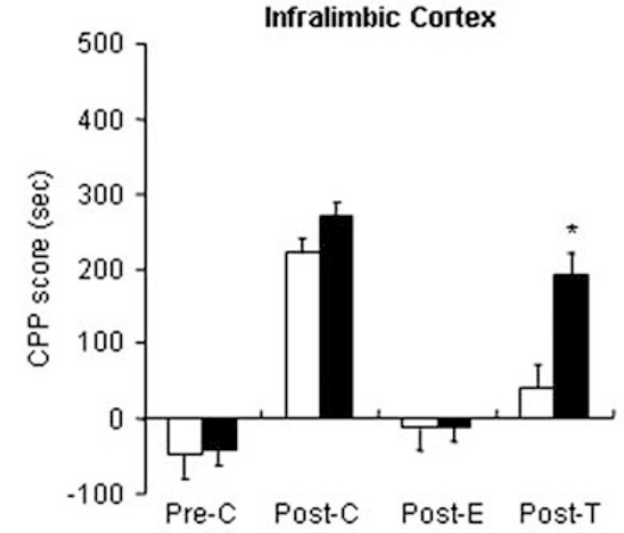

C

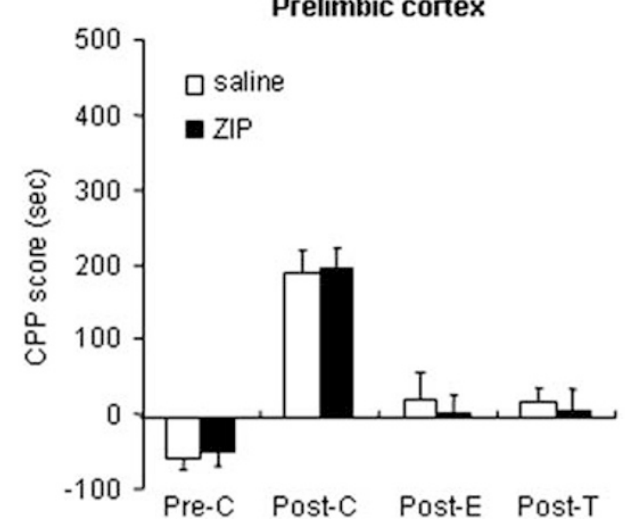

Figure 4 PKM $\zeta$ inhibition in the infralimbic cortex, but not prelimbic cortex, disrupts the maintenance of extinguished morphine-associated rewarding memory. (a) Timeline of experimental procedure. (b, c) Rats were trained for morphine-induced CPP and then underwent extinction training for 8 days. ZIP ( $30 \mathrm{nmol} / \mathrm{side})$ and its vehicle were microinfused bilaterally into the infralimbic cortex or prelimbic cortex I day after the extinguished CPP test, and the preference was retested I day after microinfusion. Data are expressed as the mean \pm SEM of preference scores in seconds (time spent in the morphine-paired chamber minus time spent in the saline-paired chamber) during the CPP tests. $* p<0.05$, different from control group ( $0 \mathrm{nmol} / \mathrm{side}$ ZIP treatment group).

Experiment 5: effects of $P K M \zeta$ inhibition in the prefrontal cortex on extinction memory of morphine withdrawalassociated aversion. We used four groups of rats $(n=7-8$ per group) to determine the effects of $\mathrm{PKM} \zeta$ inhibition in the prefrontal cortex on extinction memory of morphine withdrawal-associated aversion (Figure 5a). The rats were trained for CPA for 8 days and tested for the expression of CPA on day 9 (post-C). The rats then underwent 8 consecutive days of extinction training. On day 18, the rats underwent another CPA test to confirm that CPA was extinguished (post-E). On day 19, the rats were injected with ZIP $(30 \mathrm{nmol} / \mathrm{side})$ or vehicle into the two subdivisions of a

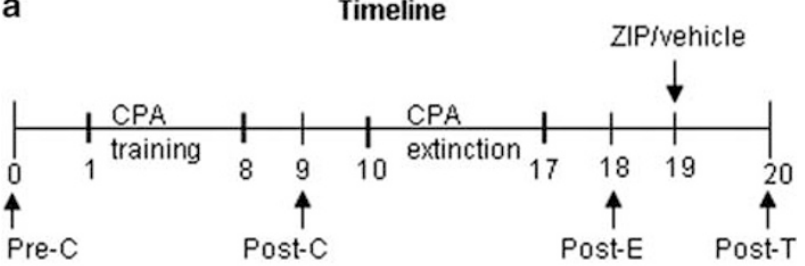

b

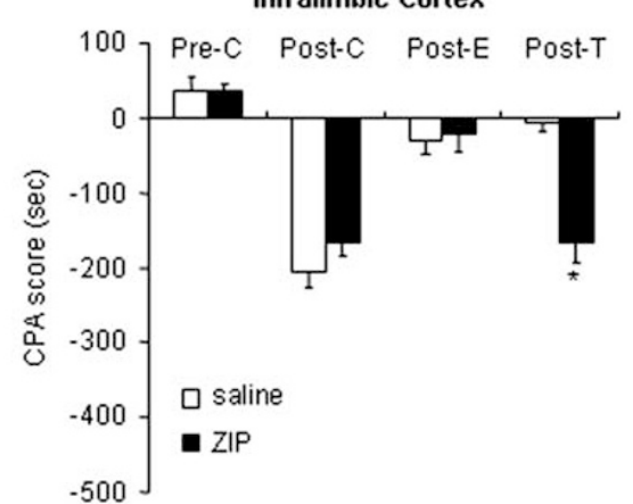

C

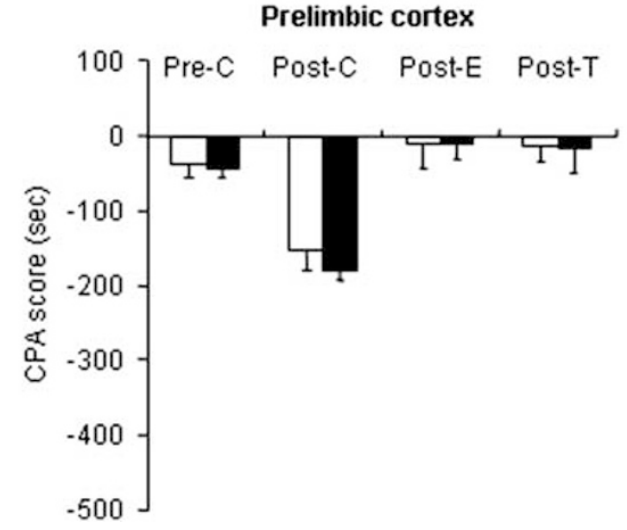

Figure $5 \mathrm{PKM} \zeta$ inhibition in the infralimbic cortex, but not prelimbic cortex, disrupts the maintenance of extinguished morphine/naloxoneassociated aversive memory. (a) Timeline of experimental procedure. (b, c) Rats were trained for morphine withdrawal-induced CPA for 8 days and then underwent extinction training for 8 days. ZIP ( $30 \mathrm{nmol} / \mathrm{side})$ and its vehicle were microinfused bilaterally into the infralimbic cortex or prelimbic cortex I day after the extinguished CPA test, and the CPA was retested I day after microinfusion. Data are expressed as the mean \pm SEM of aversion scores in seconds (time spent in the morphine withdrawal-paired chamber minus time spent in the saline-paired chamber) during the CPA tests. $* p<0.05$, different from control group $(0 \mathrm{nmol} / \mathrm{side}$ ZIP treatment group).

prefrontal cortex, infralimbic cortex, or prelimbic cortex. Twenty-four hours after the injection, the expression of CPA was retested (post-T).

\section{Statistical Analyses}

The data are expressed as mean \pm SEM. The statistical analysis was performed using two-way analysis of variance (ANOVA), with CPP score as the dependent factor. Post hoc analyses of significant effects in the ANOVA were performed using the Tukey's test. Values of $p<0.05$ were considered statistically significant. 


\section{RESULTS}

Inhibition of PKM $\zeta$ Activity in the BLA Impaired the Maintenance of Morphine-Associated Reward Memory

In experiment 1 , a two-way repeated-measures ANOVA conducted on CPP scores, with treatment (ZIP or saline) as the between-subjects factor and test condition (preconditioning, post-conditioning, and post-treatment) as the within-subjects factor, revealed significant effects of treatment $\left(\mathrm{F}_{1,14}=20.7, p<0.01\right)$ and test condition $\left(\mathrm{F}_{2,28}=\right.$ $15.39, p<0.01)$ and a treatment $\times$ test condition interaction $\left(\mathrm{F}_{2,28}=3.39, p<0.05\right)$ in the BLA. The analysis revealed no significant effects of treatment and no treatment $\times$ test condition interaction in the CeA $(p>0.1)$. The post hoc analysis revealed that all groups acquired CPP after training, but $24 \mathrm{~h}$ after ZIP or saline was infused into the BLA or CeA, CPP scores significantly decreased in the group of rats that received a ZIP infusion into the BLA in the postT1 test (Figure 1b). CPP was not altered in the group of rats that received a ZIP infusion into the CeA (Figure 1c). These results indicate that $\mathrm{PKM} \zeta$ inhibition in the BLA, but not $\mathrm{CeA}$, impaired the maintenance of morphineinduced CPP.

\section{The Impairment of Morphine Reward Memory Induced by PKM $\zeta$ Inhibition in the BLA is Long Lasting}

ZIP injections into the BLA abolished the expression of morphine-induced CPP on days 11,18 , and 25 , indicating that the disruption of the maintenance of morphineinduced CPP by ZIP injections into the BLA persisted for at least 2 weeks. CPP scores were analyzed with a mixed ANOVA, with ZIP (ZIP, scr-ZIP, vehicle) as the betweensubjects factor and test condition (post-C, post-T1, post-T7, and post-T14) as the within-subjects factor. The ANOVA revealed significant differences in CPP scores for ZIP $\left(\mathrm{F}_{2,22}=7.29, p<0.01\right)$ and test condition $\left(\mathrm{F}_{3,66}=5.18\right.$, $p<0.01)$ and a ZIP $\times$ test condition interaction $\left(\mathrm{F}_{6,66}=\right.$ $2.96, p<0.01)$. The post hoc analysis revealed that all groups of rats acquired CPP after training. CPP scores significantly decreased in the groups of rats that received ZIP infusions into the BLA in the post-T1, post-T7, and post-T14 tests (Figure 2b). Experiments 1 and 2 indicate that $\mathrm{PKM} \zeta$ activity in the BLA maintains morphine-associated reward memory.

\section{Inhibition of PKM $\zeta$ Activity in the BLA Impaired the Maintenance of Morphine Withdrawal-Associated Aversive Memory}

In experiment 3, we examined whether morphine withdrawal-associated aversive memory is also maintained by $\mathrm{PKM} \zeta$ by examining the effects of ZIP on CPA. Rats were trained for CPA, and $24 \mathrm{~h}$ after the injection of ZIP or saline into the BLA or CeA, CPA was retested. A two-way repeated-measures ANOVA conducted on CPA scores, with treatment (ZIP or saline) as the between-subjects factor and test condition (pre-conditioning, post-conditioning, and post-treatment) as the within-subjects factor, revealed significant effects of treatment $\left(\mathrm{F}_{1,12}=43.57, p<0.01\right)$ and test condition $\left(\mathrm{F}_{2,24}=17.28, p<0.01\right)$ and treatment $\times$ test condition interaction $\left(\mathrm{F}_{2,24}=7.58, p<0.05\right)$ in the BLA. The analysis revealed no significant effects of treatment and no treatment $\times$ test condition interaction in the $\mathrm{CeA}(p>0.1)$. The post hoc analysis showed that all groups of rats acquired CPA after training. CPA scores significantly decreased in the group of rats that received a ZIP infusion into the BLA (Figure $3 \mathrm{~b}$ ), but not CeA (Figure $3 \mathrm{c}$ ). These results suggest that $\mathrm{PKM} \zeta$ activity maintains morphine withdrawal-associated aversive memory.

\section{Inhibition of PKM $\zeta$ Activity in the Infralimbic Cortex Disrupts the Maintenance of Extinction Memory of Morphine-Induced CPP}

In experiment 4 , we tested whether $\mathrm{PKM} \zeta$ activity is required for the maintenance of CPP extinction memory. After extinction training, ZIP or vehicle was microinjected into the infralimbic or prelimbic cortex, and $24 \mathrm{~h}$ later, the expression of CPP was tested. A two-way repeated-measures ANOVA conducted on CPP scores, with treatment (ZIP or saline) as the between-subjects factor and test condition (pre-conditioning, post-conditioning, post-extinction, and post-treatment 1) as the within-subjects factor, revealed significant effects of treatment $\left(\mathrm{F}_{1,13}=41.63, p<0.01\right)$ and test condition $\left(\mathrm{F}_{3,39}=35.77, p<0.01\right)$ and a treatment $\times$ test condition interaction $\left(\mathrm{F}_{3,39}=2.89, p<0.05\right)$ in the infralimbic cortex. The analysis revealed no significant effect of treatment and no treatment $\times$ test condition interaction in the prelimbic cortex $(p>0.1)$. The post hoc analysis showed that CPP scores decreased after extinction training and recovered after ZIP injections into the infralimbic cortex (Figure 4b). However, no significant effects were observed in the group that received ZIP microinjections into the prelimbic cortex (Figure 4c). These results suggest that $\operatorname{PKM} \zeta$ activity in the infralimbic cortex maintains the extinction memory of morphine-induced CPP.

\section{Inhibition of PKM $\zeta$ Activity in the Infralimbic Cortex Disrupts the Maintenance of CPA Extinction Memory}

In experiment 5, we tested whether $\mathrm{PKM} \zeta$ activity in the infralimbic cortex is required for the maintenance of extinction memory of morphine withdrawal-associated CPA. After extinction training, ZIP or vehicle was injected into the infralimbic cortex, and $24 \mathrm{~h}$ later, the expression of CPA was tested. A two-way repeated-measures ANOVA conducted on CPA scores, with treatment (ZIP or saline) as the between-subjects factor and test condition (preconditioning, post-conditioning, post-extinction, and post-treatment 1 ) as the within-subjects factor, revealed significant effects of treatment $\left(\mathrm{F}_{1,13}=30.31, p<0.01\right)$ and test condition $\left(\mathrm{F}_{3,39}=30.10, p<0.01\right)$ and a treatment $\times$ test condition interaction $\left(\mathrm{F}_{3,39}=4.01, p<0.05\right)$. The analysis revealed no significant effect of treatment and no treatment $\times$ test condition interaction in the prelimbic cortex $(p>0.1)$. The post hoc analysis showed that CPA scores decreased after extinction training and recovered after ZIP injections into the infralimbic cortex (Figure $5 b$ ). However, no significant effects were observed in the group that received a ZIP microinjection into the prelimbic cortex (Figure 5c). These results suggest that PKM $\zeta$ activity in the infralimbic cortex maintains the extinction memory of morphine withdrawal-associated CPA. 
a Basolateral amygdala

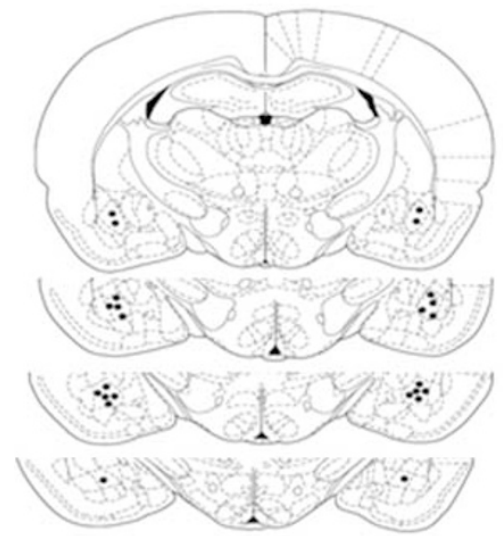

C

Infralimbic cortex

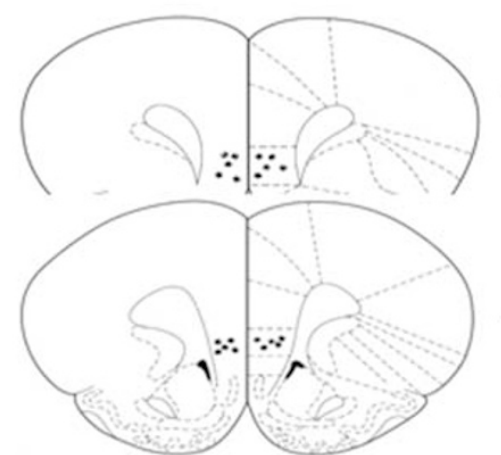

b

$-2.30$

$-2.56$

$-2.80$

$-3.14$

$+3.20$

\section{d Prelimbic cortex}

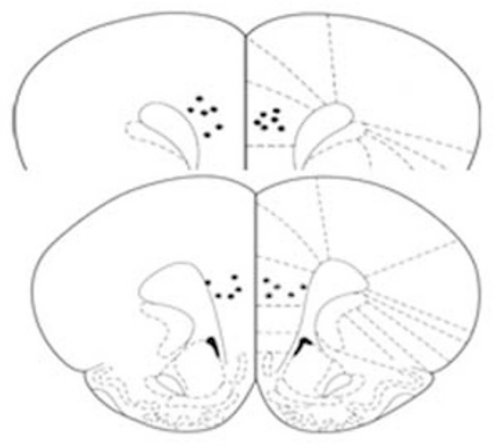

Figure 6 Schematic representation of the injection sites in the BLA (a), CeA (b), infralimbic cortex (c), and prelimbic cortex (d).

\section{DISCUSSION}

In the present study, we investigated the role of $\mathrm{PKM} \zeta$ in morphine reward-related cue memory, morphine withdrawal-associated aversive memory, and the extinction memory of drug-related cues. A single injection of the $\mathrm{PKM} \zeta$ inhibitor into the BLA, but not CeA, abolished the established morphine-induced CPP, and this effect lasted at least 2 weeks and showed no spontaneous recovery. Inhibition of $\mathrm{PKM} \zeta$ activity in the BLA, but not $\mathrm{CeA}$, abolished the established morphine withdrawal-associated $\mathrm{CPA}$. Inhibition of $\mathrm{PKM} \zeta$ activity in the infralimbic cortex, but not prelimbic cortex, after extinction of CPP and CPA restored the expression of CPP and CPA (Figure 6).

Some methodological issues should be considered in our studies. First, the memory inhibition induced by ZIP may be caused by memory extinction but not memory storage impairment, and extinguished memories may show spontaneous recovery after long-term abstinence. We found that the ZIP-induced impairment of morphineinduced CPP lasted 2 weeks and did not show spontaneous recovery. Second, some may argue that the effect of ZIP is nonspecific and may influence other protein kinases or cause lesions within the brain injection sites. We did not exclude this possibility directly, but the present study and previous studies indicated that the inhibitory effect of ZIP was specific for atypical $\mathrm{PKC} \zeta$ and not attributable to a nonspecific effect of the agent, interference with other signaling pathways, or effects on the relearning of a memory task (Li et al, 2011; Migues et al, 2010; Pastalkova et al, 2006; Shema et al, 2007). In the present study, we showed that scrambled ZIP had no effect on morphineinduced CPP. Thus, the effect of ZIP on memory impairment in our study was specific. Third, the effect of ZIP on memory impairment is anatomically specific. Inhibition of $\operatorname{PKM} \zeta$ activity in the BLA, but not CeA, erased the morphine-associated reward memory and morphine withdrawal-associated aversive memory. Similarly, inhibition of PKM $\zeta$ activity in the infralimbic cortex, but not prelimbic cortex, impaired the maintenance of extinction memory. Last, the ZIP dose $(30 \mathrm{nmol})$ was slightly larger than previous studies ( 10 or $20 \mathrm{nmol}$ ), but our recent study (Li et al, 2011) showed that $30 \mathrm{nmol}$ was more effective than $10 \mathrm{nmol}$ in disrupting morphine cue memories, which may be attributable to differences in the memory tasks (ie, spatial or fear memory $v s$ drug memory) and brain regions. Moreover, our recent study showed that $30 \mathrm{nmol}$ ZIP had no effect on locomotor activity (Li et al, 2011), so the possibility that the effect of the ZIP injections was caused by some form of motor impairment is unlikely. Our present findings are consistent with previous studies that revealed a critical role of the BLA and infralimbic cortex in drug-related memories (Peters et al, 2009; Robbins et al, 2008). 
Role of PKM $\zeta$ in the Maintenance of Drug-Seeking Behavior

Persistent drug abuse causes long-lasting neuroplasticity in the mesolimbic dopamine system, including the nucleus accumbens, prefrontal cortex, and amygdala (Hyman et al, 2006; Morgane et al, 2005; Winder et al, 2002). This abnormal neuroplasticity involves neurotransmitters, neurotrophic factors, and signaling cascades that are also implicated in normal learning and memory, including dopamine transmission, glutamate transmission, brainderived neurotrophic factor (BDNF), extracellular signalregulated kinase (ERK), and PKA (Nestler, 2004; Thomas et al, 2008). For example, increased BDNF in the nucleus accumbens augmented cocaine-seeking behavior in cocaine-induced CPP and cocaine self-administration in rats (Bahi et al, 2008; Crooks et al, 2010; Graham et al, 2007). Inhibition of ERK or PKA activity prevented the retrieval or reconsolidation of drug-related cue memory $(\mathrm{Li}$ et al, 2008; Lu et al, 2005; Sanchez et al, 2010; Valjent et al, 2006). These previous studies mainly focused on the development, expression, and stabilization of drug-seeking behavior. Few studies have investigated the mechanisms underlying the maintenance of drug-seeking behavior. Recently, we investigated the role of PKM $\zeta$ in the nucleus accumbens core in the maintenance of reward memory. We found that increased $\mathrm{PKM} \zeta$ levels in the nucleus accumbens core, but not shell, were associated with CPP training, and inhibition of $\mathrm{PKM} \zeta$ activity abolished cocaine- and morphine-induced CPP ( $\mathrm{Li}$ et al, 2011). Additionally, the impairment of reward memory by a $\mathrm{PKM} \zeta$ inhibitor occurred independently of memory retrieval and memory age. In contrast, $\mathrm{PKM} \zeta$ inhibition in the nucleus accumbens core had no effect on morphine withdrawal-associated aversive memory (Li et al, 2011). Extending our previous study, a single injection of the PKM $\zeta$ inhibitor ZIP into the BLA erased the storage of morphine reward-related cue memories and morphine withdrawal-associated aversive memories. The inhibitory effect of ZIP was not likely attributable to the prevention of retrieval or augmentation of extinction of morphine-related cue memories because CPP did not show spontaneous recovery 2 weeks after the ZIP injection. Furthermore, the inhibitory effect of PKM $\zeta$ on memory was distinct from the impairment of memory reconsolidation; the latter requires memory retrieval. To our knowledge, this is the first study to reveal the molecular basis of the maintenance of drug-seeking behavior and extinguished drug-seeking behavior.

The underlying mechanism by which $\mathrm{PKM} \zeta$ maintains drug-related memories is unknown but may involve the regulation of excitatory synaptic transmission and postsynaptic AMPA receptors. PKM $\zeta$ maintains late-LTP through upregulation of an NSF/GluR2-dependent AMPA receptor trafficking pathway (Yao et al, 2008). $\mathrm{PKM} \zeta$ acts through NSF by releasing GluR2-containing receptors from a reserve pool at extrasynaptic sites by protein interacting with $\mathrm{C}$ kinase and promoting their trafficking to the postsynaptic density (Yao et al, 2008). Recently, Migues et al (2010) found that the extent of fear memory impairment caused by $\mathrm{PKM} \zeta$ inhibition positively correlated with a decrease in postsynaptic GluR2, and blocking the GluR2-dependent removal of postsynaptic AMPA receptors abolished the impairment caused by inactivating $\mathrm{PKM} \zeta$. These results indicate that the role of $\mathrm{PKM} \zeta$ depends on the trafficking of the GluR2-AMPA receptor. Additionally, some kinases, such as ERK, PKA, and CaMKII, which have an important role in the regulation of $\mathrm{PKM} \zeta$ in LTP (Kelly et al, 2007), have also been implicated in AMPA receptor adaptations induced by repeated drug exposure (Bowers et al, 2010; Thomas et al, 2008). Thus, GluR2AMPA receptor trafficking may be critical for the maintenance of drug-related memories by $\mathrm{PKM} \zeta$, but some questions still need to be resolved (eg, whether the types of neurons that express $\mathrm{PKM} \zeta$ are different in the CPP, CPA, extinction of CPP, and extinction of CPA memory tasks, whether these alterations also occur in long-lasting memories of cues previously paired with intravenous selfinjections of drugs, and whether the downstream targets are different in the BLA, CeA, infralimbic cortex, and prelimbic cortex).

\section{General Role of PKM $\zeta$ in Memory Storage}

$\mathrm{PKM} \zeta$ is a member of the PKC family but is different from most PKC isoforms. $\mathrm{PKM} \zeta$ lacks an $N$-terminal autoinhibitory regulatory domain, which can block the activity of a $C$-terminal catalytic domain (Newton, 2001; Sacktor, 2008). Because of its special structure, $\mathrm{PKM} \zeta$ is a persistently active kinase and is sufficient for the maintenance of latephase LTP (Osten et al, 1996; Sacktor et al, 1993). Latephase LTP is considered to be the underlying mechanism of long-term memory, and $\mathrm{PKM} \zeta$ may also be required for the maintenance of long-term memory. Indeed, studies have shown that $\mathrm{PKM} \zeta$ is critical for the maintenance of hippocampus-dependent spatial memory and contextual learning (Pastalkova et al, 2006; Serrano et al, 2008) and amygdala-dependent fear memory (Kwapis et al, 2009; Serrano et al, 2008). Other studies showed that PKM $\zeta$ inhibition in the neocortex can disrupt conditioned taste aversion memory (Shema et al, 2007, 2009). Additionally, $\operatorname{PKM} \zeta$ maintained hippocampus-dependent object identity memory (Hardt et al, 2010) and sensorimotor cortexdependent instrumental memory (von Kraus et al, 2010). The present study extends these findings. We found that $\operatorname{PKM} \zeta$ maintained both reward-related cue memory and aversive cue memory. More importantly, PKM $\zeta$ also maintained extinction memory. Our results support the hypothesis that $\mathrm{PKM} \zeta$ may be a general mechanism of memory storage.

Extinction is a form of inhibitory learning that suppresses a previously conditioned response. Activity in the infralimbic subregion of the medial prefrontal cortex is a key mediator of the inhibitory memory that underlies extinction (Laurent and Westbrook, 2009; Milad and Quirk, 2002; Quirk et al, 2000, 2006). Extinction training-induced activation of the infralimbic cortex and inactivation of the infralimbic cortex, but not prelimbic cortex, impaired the consolidation and retrieval of extinction memory. Other studies showed that extinction memory requires the activation of NMDA receptors (Burgos-Robles et al, 2007), $\mathrm{CB}_{1}$ receptors (Lin et al, 2009), noradrenergic $\beta$-receptors (Mueller et al, 2008), and mGluR5 (Fontanez-Nuin et al, 2010) in the infralimbic cortex. Moreover, a recent study found that the infralimbic cortex is recruited by extinction 
training to suppress cocaine seeking (Peters et al, 2008). Our study is consistent with these findings, and we found that inhibition of PKM $\zeta$ in the infralimbic cortex, but not prelimbic cortex, erased the extinction memories of both reward-related and aversive cues. Our findings suggest that the infralimbic cortex is not only required for the retrieval and consolidation of extinction memories but also required for the storage of extinction memories. Additionally, extinction is hypothesized to not erase conditioning but rather form new memories (Cammarota et al, 2005; Quirk et al, 2006; Quirk and Gehlert, 2003; Quirk and Mueller, 2008). Similar to other forms of learning, extinction memory also occurs in several phases: acquisition, consolidation, retrieval, and reconsolidation (Quirk et al, 2006; Quirk and Mueller, 2008; Rossato et al, 2010). Our results support and extend this notion and show that, like other forms of memories, the maintenance of extinction memory also requires $\mathrm{PKM} \zeta$ activity.

\section{Concluding Remarks}

In summary, our study showed that PKM $\zeta$ in the BLA is critical for the maintenance of morphine-associated reward memory and morphine withdrawal-associated aversive memory, and the effect of $\mathrm{PKM} \zeta$ inhibition was long lasting. We also found that PKM $\zeta$ in the infralimbic cortex is required for the maintenance of extinction memories of both reward-related and aversive cues. These findings suggest that $\mathrm{PKM} \zeta$ may be a valuable new target in the study of drug-related cue memories, and the erasure of drug-related cue memories by $\mathrm{PKM} \zeta$ inhibition may be a potential therapeutic strategy.

\section{ACKNOWLEDGEMENTS}

This work was supported in part by the National Basic Research Program of China (no. 2007CB512302), Natural Science Foundation of China (no. 30725016 and 31070958), and Natural Science Foundation of Guizhou Province (no. 2008-59).

\section{DISCLOSURE}

The authors declare no conflict of interest.

\section{REFERENCES}

Azar MR, Jones BC, Schulteis G (2003). Conditioned place aversion is a highly sensitive index of acute opioid dependence and withdrawal. Psychopharmacology (Berl) 170: 42-50.

Bahi A, Boyer F, Chandrasekar V, Dreyer JL (2008). Role of accumbens BDNF and TrkB in cocaine-induced psychomotor sensitization, conditioned-place preference, and reinstatement in rats. Psychopharmacology (Berl) 199: 169-182.

Bowers MS, Chen BT, Bonci A (2010). AMPA receptor synaptic plasticity induced by psychostimulants: the past, present, and therapeutic future. Neuron 67: 11-24.

Burgos-Robles A, Vidal-Gonzalez I, Santini E, Quirk GJ (2007). Consolidation of fear extinction requires NMDA receptordependent bursting in the ventromedial prefrontal cortex. Neuron 53: 871-880.
Cammarota M, Bevilaqua LR, Barros DM, Vianna MR, Izquierdo LA, Medina JH et al (2005). Retrieval and the extinction of memory. Cell Mol Neurobiol 25: 465-474.

Childress A, Ehrman R, McLellan AT, O’Brien C (1988). Conditioned craving and arousal in cocaine addiction: a preliminary report. NIDA Res Monogr 81: 74-80.

Crooks KR, Kleven DT, Rodriguiz RM, Wetsel WC, McNamara JO (2010). TrkB signaling is required for behavioral sensitization and conditioned place preference induced by a single injection of cocaine. Neuropharmacology 58: 1067-1077.

Fontanez-Nuin DE, Santini E, Quirk GJ, Porter JT (2010). Memory for fear extinction requires mGluR5-mediated activation of infralimbic neurons. Cereb Cortex 21: 727-735.

Graham DL, Edwards S, Bachtell RK, DiLeone RJ, Rios M, Self DW (2007). Dynamic BDNF activity in nucleus accumbens with cocaine use increases self-administration and relapse. Nat Neurosci 10: 1029-1037.

Hardt O, Migues PV, Hastings M, Wong J, Nader K (2010). PKMzeta maintains 1-day- and 6-day-old long-term object location but not object identity memory in dorsal hippocampus. Hippocampus 20: 691-695.

Hyman SE, Malenka RC, Nestler EJ (2006). Neural mechanisms of addiction: the role of reward-related learning and memory. Annu Rev Neurosci 29: 565-598.

Kelly MT, Crary JF, Sacktor TC (2007). Regulation of protein kinase Mzeta synthesis by multiple kinases in long-term potentiation. J Neurosci 27: 3439-3444.

Kwapis JL, Jarome TJ, Lonergan ME, Helmstetter FJ (2009). Protein kinase Mzeta maintains fear memory in the amygdala but not in the hippocampus. Behav Neurosci 123: 844-850.

LaLumiere RT, Kalivas PW (2008). Glutamate release in the nucleus accumbens core is necessary for heroin seeking. J Neurosci 28: 3170-3177.

Laurent V, Westbrook RF (2009). Inactivation of the infralimbic but not the prelimbic cortex impairs consolidation and retrieval of fear extinction. Learn Mem 16: 520-529.

Lee AM, Messing RO (2008). Protein kinases and addiction. Ann N Y Acad Sci 1141: 22-57.

Leshner AI (1997). Drug abuse and addiction treatment research. The next generation. Arch Gen Psychiatry 54: 691-694.

Li FQ, Xue YX, Wang JS, Fang Q, Li YQ, Zhu WL et al (2010). Basolateral amygdala cdk5 activity mediates consolidation and reconsolidation of memories for cocaine cues. J Neurosci 30: 10351-10359.

Li YQ, Li FQ, Wang XY, Wu P, Zhao M, Xu CM et al (2008). Central amygdala extracellular signal-regulated kinase signaling pathway is critical to incubation of opiate craving. J Neurosci 28: $13248-13257$.

Li YQ, Xue YX, He YY, Li FQ, Xue LF, Xu CM et al (2011). Inhibition of $\mathrm{PKM} \zeta$ in nucleus accumbens core abolishes longterm drug reward memory. J Neurosci 31: 5436-5446.

Lin HC, Mao SC, Su CL, Gean PW (2009). The role of prefrontal cortex CB1 receptors in the modulation of fear memory. Cereb Cortex 19: 165-175.

Ling DS, Benardo LS, Sacktor TC (2006). Protein kinase Mzeta enhances excitatory synaptic transmission by increasing the number of active postsynaptic AMPA receptors. Hippocampus 16: $443-452$.

Lu L, Hope BT, Dempsey J, Liu SY, Bossert JM, Shaham Y (2005). Central amygdala ERK signaling pathway is critical to incubation of cocaine craving. Nat Neurosci 8: 212-219.

Madronal N, Gruart A, Sacktor TC, Delgado-Garcia JM (2010). PKMzeta inhibition reverses learning-induced increases in hippocampal synaptic strength and memory during trace eyeblink conditioning. PLoS One 5: e10400.

Migues PV, Hardt O, Wu DC, Gamache K, Sacktor TC, Wang YT et al (2010). PKMzeta maintains memories by regulating GluR2dependent AMPA receptor trafficking. Nat Neurosci 13: 630-634. 
Milad MR, Quirk GJ (2002). Neurons in medial prefrontal cortex signal memory for fear extinction. Nature 420: 70-74.

Morgane PJ, Galler JR, Mokler DJ (2005). A review of systems and networks of the limbic forebrain/limbic midbrain. Prog Neurobiol 75: 143-160.

Mueller D, Porter JT, Quirk GJ (2008). Noradrenergic signaling in infralimbic cortex increases cell excitability and strengthens memory for fear extinction. J Neurosci 28: 369-375.

Nestler EJ (2001). Neurobiology. Total recall-the memory of addiction. Science 292: 2266-2267.

Nestler EJ (2004). Molecular mechanisms of drug addiction. Neuropharmacology 47(Suppl 1): 24-32.

Newton AC (2001). Protein kinase C: structural and spatial regulation by phosphorylation, cofactors, and macromolecular interactions. Chem Rev 101: 2353-2364.

O’Brien CP, Childress AR, McLellan AT, Ehrman R (1992). Classical conditioning in drug-dependent humans. Ann $N Y$ Acad Sci 654: 400-415.

O'Brien CP, McLellan AT (1996). Myths about the treatment of addiction. Lancet 347: 237-240.

Osten P, Valsamis L, Harris A, Sacktor TC (1996). Protein synthesis-dependent formation of protein kinase Mzeta in long-term potentiation. J Neurosci 16: 2444-2451.

Pastalkova E, Serrano P, Pinkhasova D, Wallace E, Fenton AA, Sacktor TC (2006). Storage of spatial information by the maintenance mechanism of LTP. Science 313: 1141-1144.

Paxinos G, Watson C (2005). The Rat Brain in Stereotaxic Coordinates, 5 edn. Elsevier Academic Press: Amsterdam.

Peters J, Kalivas PW, Quirk GJ (2009). Extinction circuits for fear and addiction overlap in prefrontal cortex. Learn Mem 16: 279-288.

Peters J, LaLumiere RT, Kalivas PW (2008). Infralimbic prefrontal cortex is responsible for inhibiting cocaine seeking in extinguished rats. J Neurosci 28: 6046-6053.

Phelps EA, LeDoux JE (2005). Contributions of the amygdala to emotion processing: from animal models to human behavior. Neuron 48: 175-187.

Quirk GJ, Garcia R, Gonzalez-Lima F (2006). Prefrontal mechanisms in extinction of conditioned fear. Biol Psychiatry 60: 337-343.

Quirk GJ, Gehlert DR (2003). Inhibition of the amygdala: key to pathological states? Ann N Y Acad Sci 985: 263-272.

Quirk GJ, Mueller D (2008). Neural mechanisms of extinction learning and retrieval. Neuropsychopharmacology 33: 56-72.

Quirk GJ, Russo GK, Barron JL, Lebron K (2000). The role of ventromedial prefrontal cortex in the recovery of extinguished fear. J Neurosci 20: 6225-6231.

Robbins TW, Ersche KD, Everitt BJ (2008). Drug addiction and the memory systems of the brain. Ann N Y Acad Sci 1141: $1-21$.
Ron D, Jurd R (2005). The 'ups and downs' of signaling cascades in addiction. Sci STKE 2005: re14.

Rossato JI, Bevilaqua LR, Izquierdo I, Medina JH, Cammarota M (2010). Retrieval induces reconsolidation of fear extinction memory. Proc Natl Acad Sci USA 107: 21801-21805.

Russo SJ, Mazei-Robison MS, Ables JL, Nestler EJ (2009). Neurotrophic factors and structural plasticity in addiction. Neuropharmacology 56(Suppl 1): 73-82.

Sacktor TC (2008). PKMzeta, LTP maintenance, and the dynamic molecular biology of memory storage. Prog Brain Res 169: 27-40.

Sacktor TC, Osten P, Valsamis H, Jiang X, Naik MU, Sublette E (1993). Persistent activation of the zeta isoform of protein kinase $\mathrm{C}$ in the maintenance of long-term potentiation. Proc Natl Acad Sci USA 90: 8342-8346.

Sanchez H, Quinn JJ, Torregrossa MM, Taylor JR (2010). Reconsolidation of a cocaine-associated stimulus requires amygdalar protein kinase A. J Neurosci 30: 4401-4407.

Santini E, Porter JT (2010). M-type potassium channels modulate the intrinsic excitability of infralimbic neurons and regulate fear expression and extinction. J Neurosci 30: 12379-12386.

Serrano P, Friedman EL, Kenney J, Taubenfeld SM, Zimmerman JM, Hanna J et al (2008). PKMzeta maintains spatial, instrumental, and classically conditioned long-term memories. PLoS Biol 6: 2698-2706.

Shema R, Hazvi S, Sacktor TC, Dudai Y (2009). Boundary conditions for the maintenance of memory by PKMzeta in neocortex. Learn Mem 16: 122-128.

Shema R, Sacktor TC, Dudai Y (2007). Rapid erasure of long-term memory associations in the cortex by an inhibitor of PKM zeta. Science 317: 951-953.

Thomas MJ, Kalivas PW, Shaham Y (2008). Neuroplasticity in the mesolimbic dopamine system and cocaine addiction. $\mathrm{Br} J$ Pharmacol 154: 327-342.

Valjent E, Corbille AG, Bertran-Gonzalez J, Herve D, Girault JA (2006). Inhibition of ERK pathway or protein synthesis during reexposure to drugs of abuse erases previously learned place preference. Proc Natl Acad Sci USA 103: 2932-2937.

von Kraus LM, Sacktor TC, Francis JT (2010). Erasing sensorimotor memories via PKMzeta inhibition. PLoS One 5: e11125.

Wang XY, Zhao M, Ghitza UE, Li YQ, Lu L (2008). Stress impairs reconsolidation of drug memory via glucocorticoid receptors in the basolateral amygdala. J Neurosci 28: 5602-5610.

Winder DG, Egli RE, Schramm NL, Matthews RT (2002). Synaptic plasticity in drug reward circuitry. Curr Mol Med 2: 667-676.

Wise RA (2008). Dopamine and reward: the anhedonia hypothesis 30 years on. Neurotox Res 14: 169-183.

Yao Y, Kelly MT, Sajikumar S, Serrano P, Tian D, Bergold PJ et al (2008). PKM zeta maintains late long-term potentiation by $\mathrm{N}$-ethylmaleimide-sensitive factor/GluR2-dependent trafficking of postsynaptic AMPA receptors. J Neurosci 28: 7820-7827. 